\title{
The impact on midwives of their first stillbirth
}

\author{
Kay Jones ${ }^{A, B}$ MHSc (Hons), RM - Liz Smythe ${ }^{c}, \mathrm{PhD}, \mathrm{RGON}, \mathrm{RM}$.
}

${ }^{\text {A } C o r r e s p o n d i n g ~}$ Author: kay.jones@ griffith.edu.au

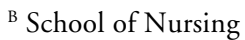
and Midwifery, Griffith University, Queensland, Australia

${ }^{\mathrm{C}}$ Auckland

University of

Technology, New

Zealand

\begin{abstract}
:
Objective: This study seeks understanding of the midwife's experiences in relation to the loss of a baby. Current research focuses mainly on the experiences of the families who have gone through stillbirth, while studies of the experience of the midwife involved in stillbirth care is lacking.

When caring for a woman who is going through a stillbirth, the midwife must navigate her own personal and professional journey.

Methods: The midwife's journey was the focus of this qualitative study which utilised hermeneutic interpretive phenomenology.

As part of a master's dissertation, five New Zealand self-employed midwives were interviewed and asked to tell their story of the first time they cared for a woman whose baby had died in utero and the aftermath of their experience.

Findings: Two emergent themes were identified: "A pocketfull of grief" and "A heavy heart". This paper focuses on the theme, "A pocketfull of grief" which is made up of three sub-themes: "Shockwave", "Self-protection" and "Blameworthiness". The death of a baby is a significant event for the midwife providing care.

Conclusion: This study has provided a deeper understanding of the emotional impact of stillbirth on the midwife. Each midwife experienced shock and an intense and personal sense of loss. This created tension as they strived to cope with their own emotions and continued to care for the woman and her family.
\end{abstract}

Key words: Phenomenology, hermeneutics, stillbirth, community-based midwifery, grief, bereavement.

\section{INTRODUCTION}

The phenomenon of stillbirth is often about suddenness, not just from the concept of the passing of time but also from a viewpoint of experiential felt unexpectedness. Suddenly the fetal heart is not there; suddenly the baby is born and despite intensive resuscitation, there is no response. Along with the family, the midwife is thrown into this crisis, sharing in their sense of loss. While the stillbirth is sudden the consequences of grief continue. This paper focuses on the impact of the initial suddenness of being at a stillbirth.

Stillbirth is defined, in Australia and New Zealand, as the death of a baby before or during birth, from the twentieth week of pregnancy onwards, or weighing 400 grams or more at birth. The current rate of stillbirth in New Zealand is $0.5 \%$ of the births recorded (ANZSA, n.d). Mitchell (2004) suggests that developments in antenatal screening have resulted in a belief that if any problem develops during a pregnancy, then obstetric intervention can solve it. Yet, in practice, the continuing incidence of unexpected stillbirths reminds us that problems may remain hidden (despite all rational screening) until it is too late. Bereaved parents turn to midwives for advice and emotional support following the death of their baby (Lovell, 2001) and this may perhaps be particularly so in the New Zealand caseload model of practice where midwives have provided continuity of care and have an ongoing relationship with the family (Davis \& Walker, 2010). There is both a professional and personal commitment to support the parents through their journey of loss and the nature of this commitment can be both complex and intricate because of the on-going connection between the midwife and the family.

The principles and priorities of providing care for women experiencing loss are well documented (Cartwright \& Read 2005; Wallbank \& Robertson, 2008) but there is little research exploring the midwives' experiences of providing care in this clinical situation. However, without the ability to manage the emotional responses to the death of a patient (baby), the practitioner may be compromised by physical, emotional, cognitive, behavioural or spiritual distress (Keene, Hutton, Hall \& Rushton, 2010).

"The Grief Response" has been described by many and often conceptualised as various stages of emotions (Kubler-Ross, 1969; Worden, 1991; Parkes, 1972). It could perhaps be better described as a roller coaster of emotions and feelings rather than a cycle or a predictable path of stages (Kubler-Ross, 1969). The most commonly experienced immediate response to the realisation of a loss is that of denial or numbness. This can be followed by anger (Kubler-Ross, 1969; Worden, 1991; Parkes, 1972). Often when denial can no longer be sustained, it is replaced with anger and self-reproach. There may be a desperate need to find someone to be angry at and, for parents, that person may be the midwife or other health professionals involved in their care. Grief and loss experts expand these responses to include depression, acceptance and finally resolution (Kubler-Ross, 1969; Worden, 1991; Parkes, 1972). 
In their exploration of midwifery care during perinatal loss, Fenwick, Jennings, Downie, Butt and Okanaga (2007) found that the midwives in their study described being emotionally overwhelmed. The midwife may try to immediately separate herself from the woman to 'buy time' to deal with her own raw emotions. In fact, the midwives felt that this was necessary to do before they were able to provide professional midwifery care for this woman. This may be a self-protective action while the midwife deals with her own response of shock and disbelief. Kohner and Henley (1991, p. 241) suggest that those who care for and support bereaved parents "may find it difficult to manage their personal reactions at the same time as performing a professional role".

In order to work through the overwhelming pain of grief the midwife may search for a way out and she may silently beg for the baby to somehow be alive and that the reality be merely a momentary misperception. Worden (1991) suggested that the midwife may promise to be a better, kinder, more watchful midwife in the future as an attempt to negotiate her way through these feelings. The phrase: "The heavy feeling that gets inside you" was suggested, by a health professional who has witnessed others' pain as a phrase that may reflect this feeling (Morrison, 2007, p.2).

\section{Many midwives may feel unprepared and inexperienced in this complex level of midwifery care regardless of their previous midwifery experience.}

The grief response and stages of responsiveness to loss may be randomly experienced by some midwives over varying periods of time. For others, in fact, these stages may be seen as only an abstract concept and not experienced in their fullness at all. For many midwives in this situation, there are questions of how do they identify their own needs, and are they even entitled to have any needs. For many midwives, death remains a mystery and they keep their own personal responses to grief silent. Consequently, the focus may be displaced onto the clinical care rather than continuing to follow the humanistic model of care that focuses on the person (Hospice Friendly Hospitals Programme, 2013). By diverting the focus away from the face of suffering, the midwife is not reminded of her own personal limits, failings and insecurities. Caring for bereaved parents after the death of a baby is emotionally challenging for some midwives (Fenwick et al., 2007). The strong desire to provide the best care under the circumstances may well be paramount to the practitioner but this is likely hampered by their own emotional response, uncertainty and anxiety. Many midwives may feel unprepared and inexperienced in this complex level of midwifery care regardless of their previous midwifery experience. There is a need to explore, understand and appreciate the lived experience of midwives who have cared for parents whose baby has been stillborn. Increasing our understanding of the potential emotional impact of such work may help the individual midwife better comprehend the experience when she finds herself faced with it for the first time and may help others to "be there" to support any midwife, providing care during and following a stillbirth.

\section{METHODS}

The methodology of hermeneutic interpretive phenomenology was chosen to help explore the lived experiences of the midwives, from their own personal vantage points (Streubert \& Carpenter, 1999). The quest was to find meaning within their narratives and to shine a light on the interpretations of their experiences. Using this methodology enables us to ensure the midwives' stories are heard when they seemingly had been silenced and therefore allows us to impart an in-depth exploration of their lived experiences.
All of the five registered practising midwives involved in this study were self-employed midwives and who had, for the first time in their midwifery practice, cared for a woman who experienced a stillbirth. None of the midwives in this study were supervising student midwives at the time that they had this experience.

Professional networks were used in order to identify suitable participants. When a midwife voiced an interest in being involved in the study, details were provided, anonymity and confidentiality issues were discussed, and information sheets sent to her, along with a consent form. Each midwife was given a pseudonym to protect her identity. The number of participants selected was based on the assumption that five different midwives, each with a unique story, would provide deep experiential data because of their own experiences of the phenomenon (Robinson, in Cluett \& Bluff, 2000). In this methodology, adequacy of data is reached when enough of the phenomenon is revealed to enable resonating similarities to emerge.

Individual interviews were conducted with each midwife and were audio-taped. The range in the duration of practice experience was from two to over twenty-five years. For the midwives in this study, their first experience of stillbirth happened between one year and eight years into their practice. The time lapse between the stillbirth and the interview was between a few months and almost a decade. The gestations of the babies lost to stillbirth were all at term and the outcome of a stillbirth was not expected in any of the cases.

The Auckland University of Technology Ethics Committee (AUTEC) granted ethical approval in August 2011. I heeded my obligation to protect the participants in my study throughout the process.

The question asked of the midwives was: "Can you set the scene for your first experience of caring for a woman having a stillbirth?" It was designed to help participants not only remember the clinical experience but also recall the thoughts and feelings associated with the event. The individual interviews were transcribed and sorted into two main thematic sections through an interpretive process. The two themes were labelled: "A pocketfull of grief" and "A heavy heart", with each theme having three sub-themes. This paper focuses on the first theme: "A pocketfull of grief".

To assist with interpretation of the data collected, Smythe and Spence's guide for "dwelling with a transcript" (1999, p.3) was utilised; that is, writing, drawing and grouping stories together looking for themes. It is suggested to use questions as prompts to delve deeper and deeper into meaning behind or below the data. The meaning of the phenomenon comes gradually as a result of careful and repeated reading, reflecting and dwelling with the data. When a researcher is using phenomenology as a research methodology, interpretation of data commences at the end of the data collection rather than during.

\section{Pre-existing understandings}

Lopez and Willis (2004) suggest that the philosophical assumption underlying interpretive phenomenology is that the knowledge of the researcher can be seen as a guide to the inquiry. Prior knowledge of the phenomenon provides context for the inquiry and can enhance the researcher's sensitivity to the data (Strauss \& Corbin, 1998). In my case, personal clinical experience as a community-based midwife and caring for women who have had a stillbirth has provided me with an understanding of the personal and professional ramifications of this situation. In addition, as I was working beside and supporting colleagues who have experienced this form of loss, I found myself questioning the effect the unstated impact of these experiences may be having on a community-based midwife. Utilising the primary author's (my) clinical experience and presumptions around caring for a woman who has had a stillbirth has added subjectivity to this research 
and aided the 'phenomenological expression' of this phenomenon (Robinson, in Cluett \& Bluff, 2000, p.153).

\section{Trustworthiness}

The ultimate test of this study's worth is that the findings ring true to the people who read it. Even if they haven't experienced the phenomenon of caring for a woman experiencing a stillbirth themselves, my aim is that by reading this research they will gain a sense of recognition from what they read. The trustworthiness of phenomenological research is critical not only to the reader but also to those who are impacted by the research (Shenton, 2004).

The purpose of this study is to draw the reader closer to the midwives' lived experiences and to offer an interpretation of their stories. For this to be useful to the reader, the trustworthiness of the findings needs to be addressed and confirmed. To affect increased likelihood that these findings become incorporated into a midwife's practice, the data need to be authentic and the discussion around these narratives has to stay true to the experience.

\section{FINDINGS}

Two main themes appeared out of the text. They represent how the midwives made sense of the experience and gave meaning to their narrative. The first theme is based on each midwife's immediate response to the death of the baby; that is, in every case a response of intense grief. This first theme is titled "a pocketfull of grief". The second theme relates to an even more personal path the midwives subsequently travelled. This theme talks of the midwives' own feelings of sadness about the loss and their personal concept of death and is titled: "a heavy heart".

This paper discusses the theme 'a pocketfull of grief which involved the initial intense response of grief and shock experienced by the participants, the depth of which often took them by surprise. Three sub-themes emerged: "shockwave", "self-protection" and finally "blameworthiness".

\section{Shockwave}

Vicky tells of being in a small birthing unit with a labouring woman and becoming concerned about the baby's heart rate. She decided to transfer the woman to the local secondary/tertiary unit for closer monitoring and obstetric support. On their arrival Vicky was unable to find the baby's heartbeat. This unexpected and sudden outcome hit her like a shockwave, a jolt that left her feeling overwhelmed.

I was sobbing so I went into the tea room and let rip. I just felt dreadful. I was a sobbing mess. All I know was that I was a distraught mess. It was shock, horror, just "Oh, my God!"

It is the suddenness of the event and her own realisation that, in fact, the baby was not alive and had died en route that find her overwhelmed with emotion. She reported experiencing a reality shock when she found herself in a situation she thought she would be prepared for, but suddenly found that she was not. They had arrived at what could be considered a "safe place", in view of the concerns she had, only to discover that it was too late. Vicky continues:
I never thought the baby would die. I knew I wanted to get her out because I wasn't happy but I didn't think that little baby would die. I thought the baby might have been born a bit flat or maybe there might be some meconium. I was prepared for that. I thought if that baby is feeling a little unhappy then I would rather it be born in the base hospital so that the paediatricians could be there. But there was never any time that I thought the baby would die.

Vicky found her emotions were difficult to contain and she felt torn between dealing with the parents' obvious feelings of devastation and containing her own personal shocked responses.
The biggest thing was trying to keep it together because the parents were so distraught. It was about them not about me...you're trying to hold back all of these emotions. That's why I let rip in the tea room. You can't get your head around the fact and then be left to catch this little baby. So perfect and so beautiful and you're just waiting for something... come on! You wait... and there is just nothing... just wishing that the baby would breathe.

Vicky felt she had to leave the room to save the woman seeing her own distress. She had tried to keep her emotions under wraps but couldn't. Out of sheer desperation to not add to the woman's pain, she needed to get away to let her own emotions out.

The woman's labour progressed extremely quickly and the baby was born. The outcome was now visible for everyone to see. The reality was confronting for all in the room: this was not a mistake; the baby had truly died. Vicky remembers waiting desperately for the baby to show signs of life. This was the one chance for the truth to be challenged. She couldn't comprehend what was actually happening because it all occurred so quickly. This would have felt surreal to Vicky not just because she had never experienced anything like this before but in her head she had a vision of how this woman would birth and nothing she was now witnessing was part of that vision.

\section{Her relationship with the woman had naturally formed a sense of attachment that made the shockingness of the loss even more overwhelming.}

By the time the parents left the hospital, Vicky hadn't slept for hours. She had travelled to the hospital with the woman in the ambulance so had to find her own way back home which was some distance away.
You could imagine with no sleep, I was just a crying, tired mess. I waited until they were discharged because I didn't feel that I could leave. I didn't know what to do. Do you leave them to their own devices to look at their baby or do they want someone around? I didn't know what to do so I just waited. They didn't want a post-mortem so they carried their baby out in a little box. You don't expect to see that. You know, what do you say to them?

The possibility of the baby being stillborn was not thought of and not expected. This description of being shocked illustrates that Vicky too, was affected by the death of the baby. Her relationship with the woman had naturally formed a sense of attachment that made the shockingness of the loss even more overwhelming.

\section{Self-protection}

The suddenness of a precipitate labour and subsequent unplanned homebirth where the baby was stillborn, left Mary confused and searching for a way to process what had happened.
I didn't understand. I thought that babies who come that quickly usually come out screaming. It was such a shock. It was just so unexpected. Just the last thing I expected to happen. I didn't know what to do. It was all very new to me.

After Mary had completed all the appropriate care for the woman, she felt she needed to distance herself from the raw reality. 
I didn't go home until about 5 pm that evening. I hung-out at the hospital. I just hung-out wherever. I hung-out at my colleague's house. I had a bath at her place. She said 'You need to go home...can I ring your partner and tell him what happened?' But I didn't want to talk to him. The hardest thing was just telling him. It's just telling people. I didn't want anyone else to know. If I could have kept it to myself and have no one else know about it, I would have.

As a form of self-protection Mary tells of "running away" to her colleague's house as she couldn't cope with having to explain, to anyone else, what had just happened. She could hardly make sense of it herself. By telling anyone else she would make the experience real. By keeping the details to herself and not letting anyone else know, she could maintain the facade of everything being alrightalmost as if it had never happened. In essence, perhaps she was "buying" some emotional time to come to terms with the reality of the loss. Mary saw her colleague's home as a safe place; a place where explanations were not necessary. The experience could be contained and kept "invisible", even for a little while longer. The symbolism of 'having a bath' could be seen as Mary needing to wash the events of the day away; to rid herself of the burden she felt she was carrying.

\section{As with any adverse outcome involving birth, the midwife involved will be required to account for her practice.}

Mary used the strategy of denial as a way of protecting herself from what she dreaded: the undeniable fact she had been the midwife for a baby who was born 'still'.
I remember Samantha, a midwife at the hospital, looking at me and looking like all she wanted to do was give me a cuddle. I said "You can't look at me like that because I am going to burst into tears". I didn't want that at all. Everyone would look at you and be thinking "I am so sorry". Sometimes sympathy is really hard. People would show it in their eyes.

Mary tried to avoid talking about her experience, wishing that people would soon forget about it; almost wanting it to be forgotten to pretend it never happened. Her emotions were tender and close to the surface like a newly healed wound. Mary conceptualised the meaning of sympathy as an agonising reminder of what had happened. She chose to keep a low profile, waiting for the intensity of the situation to settle down. She may have felt her own grief response to the stillbirth was open to misinterpretation and that her vulnerabilities would become "visible" to others. It was safer to deny it ever happened.

\section{Blameworthiness}

As with any adverse outcome involving birth, the midwife involved will be required to account for her practice. Reviewing and considering her care provision may involve self-doubt together with questioning as to whether she could have done things differently. This can often be prolonged and distressing. In her assessment, the midwife, Jill, felt the woman was labouring well and everyone was expecting the baby to be born alive and well. That was until the baby was born.

The baby was so pale and floppy. Just like a rag doll. My heart just went "thump" down to the floor. I looked up when I was doing CPR and she knew that the baby hadn't cried after the birth and she kept looking at me. I could feel her looking at me. Then in the end she said, "no, give me my baby...you know as well as I do, Jill, that my baby is dead." So I just gave her the baby and she cuddled it.

For Jill, the woman's sense of knowing would have been bittersweet. She wouldn't need to break the news to the mother but the longer she stayed focused on helping the baby, the longer she could avoid acknowledging the truth of what had just happened.

I felt that I had missed something and that I should have been able to make that baby come alive. I don't know why, it's just I have live bubbies, not dead ones. Why did it happen..? What did I do wrong..? What didn't I see happening..? Yeah... all those sorts of things. It was really raw emotions. We were all sort of in a daze and to be quite honest I don't remember what happened after that. I think you blame yourselffor something like this. More than you think you do.

The self-doubt was overwhelming for Jill and she remembers finding a hiding place to cry. This allowed her to let go of some of her own responses of shock and disbelief. She believed that she alone was accountable for what had happened. She reproached herself for missing some signal that the baby had tried to give her that it was in danger. She condemned her own practice, even after years of being a midwife. The impact of these thoughts were so great that Jill has deleted these details from her memory and stated that she couldn't remember what happened after that. The extended family called a meeting the following day to get answers to their questions.

I had to re-live it all again and I had to go back to where it
was quite sore and hurtful but at the same time it was quite
healing in a way. I'm pleased that the family know now that
I did try my very best. But that is what you do anyway. But
even now when you meet them in the street you think, "Oh,
dear, there's the family". Your heart takes a skip. It's not a
frightened skip; it's just a skip.

If a baby is born still, the usual common assumption may be made that the midwife did not live up to the shared expectations. When outcomes do not show themselves as being the epitome of perfect, the midwife may potentially feel responsible.

\section{DISCUSSION}

With the emergence of the first theme of this research, a deeper understanding was gained of the lived experience of communitybased midwives who have cared, for the first time, for a woman who has had a stillbirth.

When a baby is stillborn, the woman, her family and the midwife caring for her enter a time and place of loss and pain. The woman and her family are expecting a healthy, live baby; a baby that has been in their dreams, and its arrival intensely anticipated. For the midwife, she too, is expecting a healthy, live baby but from her training and experience, she is also aware of the twists and turns pregnancy and birth can take, sometimes without reason or warning.

\section{When a baby is stillborn, the woman, her family and the midwife caring for her enter a time and place of loss and pain.}

These findings suggest that we are often thrown into situations rather than consciously choosing to enter a particular situation. Heidegger's (1962) notion of "thrown-ness" implies that the midwife needs to make sense of where she has been thrown, or where she has been placed, in relation to the experience of being there at the moment of stillbirth. She finds herself suddenly "thrown" into a place or situation that was unexpected; in fact 
the exact opposite of what was expected, unforeseen and always alarming. So she is forced to confront where she has "landed" rather than being able to run from it, evade it, or cover it over. By metaphorically turning around to face the reality that there is no escaping this truth, the truth becomes embedded in the lived world of the midwife. It is then that death becomes real to her and the realisation that there is nothing she can do about it. They are involved in this tragedy, whether they want to be or not.

Perhaps the most challenging revelation of these research findings is the notion of the midwives experiencing a grief that isn't seen as belonging to them. Each midwife's testimony confirms that, although the loss was not theirs, their own sense of loss was intense and deeply personal. In other words, the midwife is involved intimately with the loss yet the loss is not hers to openly grieve over. Her public sorrow is for the woman's loss but her private sadness is for herself. The complexities surrounding this situation can find the midwife drawn beyond herself to a place that challenges her sense of self in a profound way. Her experience can be mysterious and exquisite, touching and tragic, scary and sacred, all at the same time.

For most, their emotions were only able to be visible for the briefest of moments. They felt their true feelings needed to be hidden and only acknowledged in their own private world during self-reflection. They found themselves experiencing the loss of a baby from a place on the outside looking in, as if in the shadows.

\section{The intensity of each midwife's story, of caring for a woman who has had a stillbirth,reflects the deeply personal journey travelled.}

These findings could suggest that the midwife felt a sense of loss in her core-self, a place of essence, where personal meaning and understanding sit. The midwife was part of the woman's reality and felt her emotions. It could be interpreted from the stories of the midwives that this empathy was a double-edged sword for the midwife. On the one hand, this empathy demonstrates "being-with" the woman; on the other hand, the act of "being" leaves the midwife vulnerable to this very act in the event of this outcome. It is suggested that the act of "being-with" the woman or attending the woman, is linked to the midwife's perception of her experience and her relationship to the world she is in (Heidegger, 1962). This concept of "being-with" the woman is not just a physical locality but a journey travelled together. The findings of this research suggest that the journey through the loss of a baby is navigated personally and privately by each midwife in contrast to the journey travelled when there is a live baby. Each step of the way, the midwife steers her way between providing situationsensitive care to the woman and her family, and coping with her own intense, overwhelming feelings that are necessarily hidden and unspoken. There is no map to follow on this journey but rather a sense of finding your way. When I reflected on the first theme developed from hearing these five midwives' stories, the theme suggested that they came out of this experience with a sense of shock and unpreparedness. Individually, each midwife gained practice wisdom which cannot be taught nor scripted. They were taken into uncharted territory and each deciphered the experience in their own unique way.

The intensity of each midwife's story, of caring for a woman who has had a stillbirth, reflects the deeply personal journey travelled. The midwife is entrenched in the woman's experience and this, in turn, brings the midwife into the experience loop that encircles them both. Although each midwife attempts to unravel her experience from her own personal perspective, there are commonalities that are apparent. The sense of loss is highlighted and this is common to both the midwife and the woman. The midwife is seen to be searching for meaning, searching for solace and searching for validation of both herself and her midwifery practice. A midwife's "life-world" or personal reality exposes the professional caring reality and illustrates the closeness of the involvement a midwife has with the woman and her family during the birth of a baby (Heidegger, 1962). The midwife "bears witness" to the event and is compelled to be involved and is bound to experience commonly felt emotions by just "being there". For the midwife, the meaning found in the shared experience is what nurtures her own practice wisdom and highlights the "being of midwifery", or in other words, the total immersion into the shared experience.

\section{LIMITATIONS OF THE STUDY}

For this study I chose to explore stillbirth from the perspective of the self-employed midwife in the New Zealand context of maternity care. This was not intended to negate other situations of bereavement care but rather to hear the stories of midwives who had cared for women who experienced the phenomenon of stillbirth as an unexpected outcome of the birth rather than when they were anticipating a stillbirth. Within the limitations of this master's study, I was unable to explore other aspects of bereavement care and particularly was unable to explore the stories and experiences of hospital employed midwives. However, the themes that emerged from these stories may resonate with other midwives regardless of their workplace setting. If so, then I can claim they usefully represent the commonality of experiences of all midwives who care for women who have had a stillbirth.

\section{Implications for practice}

The themes identified have encapsulated the message that for these midwives the experience of their very first stillbirth had a significant impact on their emotional wellbeing, both professionally and personally. These findings may resonate with other midwives and, it is hoped, will provide a better understanding of the impact of that initiatory stillbirth on the midwife. It appears that as the scenario of sudden stillbirth unfolds, the midwife's relationship with the family may intensify as the shared experience is realised. It is important that the midwife's colleagues understand the ebb and flow of emotional vulnerability both during and following a stillbirth. There is a need for support for both the woman and the midwife. There is equally a need for an understanding of the individuality of the midwives' emotional responses which may vary between shock, denial and self-blame. One notable recommendation arising from these data is to encourage the midwife to acknowledge and accept the emotions she is feeling and be helped to manage her emotions effectively as a way of recognising or supporting her own resilience.

\section{CONCLUSION}

This research has added to our knowledge of the experiences and impact of stillbirth on the midwife by exploring the reactions of five midwives to their first involvement with an unexpected stillbirth. They described feelings of shock, denial and self-blame. These build on the enduring impression of the initial sheer suddenness of being present during an immediate stillbirth, which was the focus of this paper. The participants described the tension of continuing to care for the woman and her family, and coping with their own intense feelings. The findings illustrate the impact of having the experience of a stillborn baby is one that is shared by the woman, her family and also the midwife. Although the loss is not the midwife's, these findings endorse the conclusion that the impacts on the continuity of care midwife involve feelings of loss and grief, when a baby is stillborn. 


\section{ACKNOWLEDGEMENT \& DISCLOSURE}

The author has no conflict of interest. The midwives, who shared their deeply personal and often painful memories, are acknowledged with respect and sincere gratitude. Although the families who went through the stillbirth of a baby were not known to the author, the greatest of heartfelt sympathies are conveyed to them.

\section{REFERENCES}

Australian and New Zealand Stillbirth Alliance (ANZSA) (n.d) Australia and New Zealand fact sheet. Retrieved from http://www.sidsandkids.org/ wpcontent/uploads/Lancet launch ANZSA Factsheet.pdf

Cartwright, P., \& Read, S. (2005).Working with practitioners to develop training in peri-natal loss and bereavement: Evaluating three workshops. Nurse Education in Practice, 5(5), 266-273

Davis, D.L., \& Walker, K. (2010). Case-loading midwifery in New Zealand: Making space for childbirth. Midwifery, 26(6), 603-608.

Fenwick, J., Jennings, B., Downie, J., Butt, J., \& Okanaga, M. (2007) Providing perinatal loss care: Satisfying and dissatisfying aspect for midwives. Women and Birth, 20, 153-160

Heidegger, M. (1962) Being and Time. Oxford, United Kingdom: Basil Blackwell.

Hospice Friendly Hospitals Programme (2013) End-of-Life Care \& Supporting Staff; a literature review. Retrieved from: www. hospicefriendlyhospitals.net

Keene, E.A., Hutton, N., Hall, B., \& Rushton, C. (2010). Bereavement Debriefing Sessions: An intervention to support health care professionals in managing their grief after the death of a patient. Paediatric Nursing 36(4): 185-189

Kohner, N., \& Henley, A. (1991). When a baby dies- The experience of late miscarriage, stillbirth and neonatal death. London, United Kingdom: Pandora Press.

Kubler-Ross, E. (1969) On death and dying. New York, NY: Scribner.

Lopez, K.A., \& Willis, D.G. (2004). Descriptive versus interpretive phenomenology: Their contributions to nursing knowledge. Qualitative Health Research doi: 10.1177/1049732304263638

Lovell, A. (2001). The challenging identities of miscarriage and stillbirth. Bereavement Care, 20(3), 37-40.

Mitchell, M. (2004). Preparing student midwives to care for bereaved parents. Nurse Education in Practice. March 2005; 5(2):78-83

Morrison, Z. (2007) 'Feeling heavy': vicarious trauma and other issues facing those who work in the sexual assault field. Australian Institute of Family Studies. No 4 Sept. 2007

Parkes, C. (1972) Bereavement: Studies of grief in adult life. London, England. Tavistock.

Robinson, A. (2000) Phenomenology. In Cluett, E.R. \& Bluff, R. (Eds.), Principles and practice of research in midwifery. Chapter 8, pp. 149-163) London, United Kingdom. Bailliere Tindall

Shenton, A.K. (2004) Strategies for ensuring trustworthiness in qualitative research projects. Education for Information 22 (2004) 63-75 Smythe, E. \& Spence,D. (1999). Doing phenomenological/hermeneutic research: A guide for beginners. AUT Masters of Health Science Qualitative Research Handout.

Strauss, A., \& Corbin, J., (1998) Basics of qualitative research techniques and procedures for developing grounded theory. (2nd Ed.) Sage Publications, Thousand Oaks, CA.

Streubert,H.J., \& Carpenter, D.R. (1999) Qualitative research in nursing: advancing the humanistic imperative. (2nd Ed.) Lippincott, Philadelphia Wallbank, S. \& Robertson, N. (2008) Midwife and nurse responses to miscarriage, stillbirth and neonatal death: a critical review of qualitative research. Evidence Based Midwifery 6(3):100-6

Worden, J.W. (1991). Grief counselling and grief therapy: A handbook for the mental health practitioner. (2nd ed.) London, England; Springer.

\section{Accepted for publication March 2015}

Jones, K., \& Smythe, E. (2015). The impact on midwives of their first stillbirth. NZCOM Journal 51, 17-22.

http://dx.doi.org/10.12784/nzcomjnl51.2015.3.17-22

\section{Would you like to publish in the Journal?}

Share your knowledge, experiences and research with your New Zealand and International colleagues:

If you are in postgraduate study or undertaking a research project we would like to hear from you - email: practice@nzcom.org.nz or visit www.midwife.org.nz/ resources-events/nzcomjournal for more information

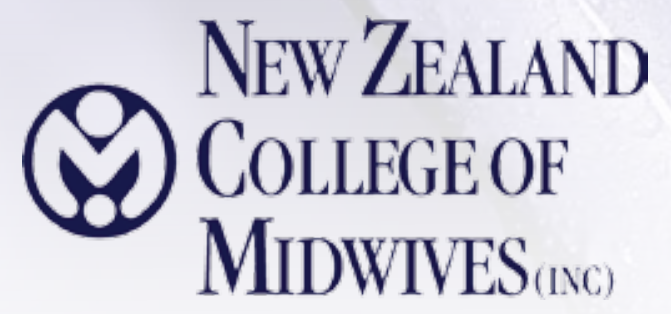

